BRITISH MEDICAL JOURNAL VOLUME $292 \quad 18$ JANUARY 1986

pressing need for culturally acceptable educational aids that recognise the regional differences between Asian communities. Such aids should encourage a reduced consumption of refined carbohydrates and saturated fats and an increased consumption of unrefined carbohydrates rich in fibre.

We gratefully acknowledge research grants from the North West Thames Regional Health Authority (locally organised research scheme) and the join finance scheme of Brent Health Authority and Brent social services.

1 Paul AA, Southgate DAT. McCance and Widdowson's the composition of foods. 4th ed. London HMSO, 1978.

2 Tan SP, Wenlock RW, Buss DH. Immigrant foods. Second supplement to McCance and Widdowson's the composition of foods. London: HMSO, 1985.

the composition of foods. London: HMSO, 1985 .
3 Nutrition subcommittee of the medical advisory committee of the British Diabetic Association. Dietary recommendations for diabetics for the 1980s. A policy statement by the British Diabetic Dietary recommendations for diabetics for the 1980s. A
Association. Hum Nutr Appl Nutr 1982;36A:378-94.

4 West KM, Kalbfleisch JM. Influence of nutritional factors on the prevalence of diabetes. Diabetes

1971;20:99-108.
5 Patel JC, Metha AB, Dhirawani MK, Juthani VJ, Aiyer L. High carbohydrate diet in the treatment of diabetes mellitus. Diabetologia 1969;5:243-7.

(Accepted 14 October 1985)

Nutrition and Diabetes Research Group, Willesden Hospital, Brent, London NW10 3RY

DAVID B PETERSON, MA, MRCP, Medical Research Council training fellow

JAYSHREE T DATTANI, BSC, DIPHUMNUTR, research nutritionist

JUDITH M BAYLIS, MSC, SRD, research dietitian

EWART M JEPSON, MD, FRCP, consultant physician

Correspondence to: Dr Peterson.

\section{Neuroleptic malignant syndrome associated with inappropriate antidiuresis and psychogenic polydipsia}

The neuroleptic malignant syndrome is a life threatening complication of major tranquillisers that is probably underdiagnosed. The factors that precipitate it are not clear. I report a case in which on two occasions hyponatraemia was initially thought to be responsible for the neurological symptoms and signs. The hyponatraemia was later shown to be due to inappropriate antidiuresis, probably associated with psychogenic polydipsia, and this may have precipitated the syndrome.

\section{Case report}

The patient was a 41 year old man who for many years had been treated with depot injections of flupenthixol and oral orphenadrine for chronic schizophrenia. He did not take any other drugs but smoked 60 cigarettes daily and drank at leas 15 litres of fluid daily, mostly in the form of instant coffee. In August 1984 he was found unconscious at home. He was admitted to hospital semiconscious and found to have greatly increased muscle tone. He was clinically normovolaemic and feverish $\left(39^{\circ} \mathrm{C}\right)$, and blood pressure fluctuated between $100 / 60$ and $170 / 120$ $\mathrm{mm}$ Hg. Dipstick testing of the urine gave a ++ reaction for blood. White cell count was $28.3 \times 10^{9} / 1$; serum sodium concentration $115 \mathrm{mmol}(\mathrm{mEq}) / 1$; serum calcium $1.97 \mathrm{mmol} / 1(7.9 \mathrm{mg} / 100 \mathrm{ml})$; serum aspartate transaminase $830 \mathrm{IU} / 1$; serum creatine phosphokinase $2438 \mathrm{U} / 1$; measured serum osmolality 251 mosmol/kg; calculated serum osmolality $250 \mathrm{mmol} / \mathrm{l}$; urine osmolality 317 mosmol/kg; and urine sodium $35 \mathrm{mmol} / 1$. His condition was complicated by hypoxia (thought to be due to decreased compliance of the chest wall), oesophagitis, and acute renal failure (thought to be due to acute rhabdomyolysis) that necessitated temporary peritoneal dialysis. After recovery of normal renal function the serum sodium concentration remained normal, even when he resumed his previous intake of fluids on discharge. Depot injections of flupenthixol were continued.

Eight months later he was readmitted after collapsing at home. On admission he was agitated, dysarthric, and feverish with increased muscle tone, hyperreflexia, and a decreasing level of consciousness. He was clinically normovolaemic, but blood pressure again fluctuated between $120 / 80$ and $240 / 140 \mathrm{~mm} \mathrm{Hg}$. On admission serum sodium concentration was $118 \mathrm{mmol} / 1$; serum osmolality $249 \mathrm{mosmol} / \mathrm{kg}$; urine osmolality $421 \mathrm{mosmol} / \mathrm{kg}$; and urine sodium $123 \mathrm{mmol} / 1$. There was no evidence of rhabdomyolysis, and renal function remained normal His serum sodium concentration and conscious level returned to normal over three days. One week later excretion of a water load was normal. Thyroid function tests gave normal results, as did a Synacthen test and insulin stress test.

\section{Comment}

The neuroleptic malignant syndrome is an idiosyncratic reaction to neuroleptic drugs characterised by muscular rigidity, hyperthermia, auto- nomic instability, and altered consciousness and is often complicated by aspiration pneumonia, oesophagitis, and acute renal failure. The syndrome bears some similarities to malignant hyperthermia but is probably underdiagnosed. Treatment is supportive, although there is limited evidence of benefit from dantrolene and dopaminergic agents. ${ }^{1}$ The syndrome may develop after years of uneventful treatment with a neuroleptic, and the factors that precipitate it are not known but are thought to include infection and dehydration. Hyponatraemia was reported as the possible precipitant in one case. ${ }^{2}$ The fact that the neuroleptic drug may be reintroduced after recovery from the syndrome without causing a further episode indicates that such trigger factors are important.

In our patient the syndrome of inappropriate antidiuresis may have acted as the trigger factor on two occasions. This in turn may have been caused by psychogenic polydipsia, ${ }^{3}$ although a direct effect of fluphenazine on release of antidiuretic hormone cannot be discounted. ${ }^{4}$ Antidiuresis of rapid onset with rapid recovery after a period of enforced fluid deprivation has been reported in patients with psychogenic polydipsia, ${ }^{5}$ although the mechanism remains unknown. Having seen another patient with hyponatraemia and the neuroleptic malignant syndrome previously, I believe that the syndrome goes unrecognised because the presenting features are attributed to hyponatraemia alone. Accurate diagnosis is important as it would allow appropriate supportive measures to be undertaken and complications to be anticipated.

I thank Dr K Evemy and Dr R G Farquharson for their permission to report on this patient and Dr P Bayliss for his advice on the patient's management.

1 Guze BH, Baxter LR. Current concepts: neuroleptic malignant syndrome. $N$ Engl $\mathcal{f}$ Med 1985;313:163-6.

2 Wedzicha JA, Hoffbrand BI. Neuroleptic malignant syndrome and hyponatraemia. Lancet 1984;: 963 .

3 Robertson GL. Psychogenic polydipsia and inappropriate antidiuresis. Arch Intern Med 1980;140 1574-5.

4 De Rivera $M$. Inappropriate secretion of antidiuretic hormone in patients receiving fluphenazine. Ann Intern Med 1975;82:811-2.

5 Kramer DS, Drake ME. Assessment of SIADH in psychosis with a water-loading test: case report. f Clin Psychiatry 1984;45:40-1.

(Accepted 15 October 1985)

Department of Medicine, Freeman Hospital, Newcastle upon Tyne NE7 7DN

C R V TOMSON, BM, MRCP, registrar

\section{Exceptional case of survival in cold water}

People immersed after shipwreck in water colder than $6^{\circ} \mathrm{C}$ usually die of hypothermia within 75 minutes. ${ }^{1}$ We know of no first hand account of survival for many hours in such water, though there is an anecdotal account. ${ }^{2}$ In laboratory experiments thick subcutaneous fat allowed volunteers to maintain body temperature for a time in water at $5^{\circ} \mathrm{C}$, but after 30 minutes cold vasodilatation caused them to cool progressively. ${ }^{3} \mathrm{We}$ report investigations on a man who survived prolonged immersion in water at $5-6^{\circ} \mathrm{C}$.

\section{Case history and investigations}

The subject, a 23 year old Icelander, had been fishing off Iceland when his boat capsized at about $10 \mathrm{pm}$ on 11 March 1984 . Water temperature was $5-6^{\circ} \mathrm{C}$ and air temperature $-2^{\circ} \mathrm{C}$. He and two out of four companions climbed on to the keel but after about 45 minutes swam towards shore, about $5 \mathrm{~km}$ ( 3 miles) away. His two remaining companions disappeared within 10 minutes. Wearing shirt, sweater, and jeans, he swam five to six hours to shore. He remained clear headed throughout.

\section{EXPERIMENTAL IMMERSION}

The following experiment was carried out 17 months after the accident.

The subject was immersed to the neck for 83 minutes in thermostatically controlled water at $5 \cdot 3-5 \cdot 4^{\circ} \mathrm{C},{ }^{4}$ air $21^{\circ} \mathrm{C}$, clothed as during his swim. He exercised arms and legs to mimic the swim, with water driven backwards past him at $500 \mathrm{~mm} / \mathrm{s}$. Metabolic rate, temperatures, heat flows, and fat thickness were measured as described. ${ }^{4}$

Results-The subject was a large man, with a height of $1.93 \mathrm{~m}$, weight $125 \mathrm{~kg}$, and surface area $2.54 \mathrm{~m}^{2}$. Subcutaneous fat thicknesses were biceps $9 \mathrm{~mm}$, thigh $10 \mathrm{~mm}$, abdomen $26 \mathrm{~mm}$, and subcostal $25 \mathrm{~mm}$, giving an overall mean subcutaneous fat thickness of $14 \mathrm{~mm}^{4}$; at maximum width of forearm (flexor 
surface) $7 \mathrm{~mm}$, and calf $9 \mathrm{~mm}$. Initial discomfort on entering cold water largely disappeared in two to three minutes. Skin temperatures fell within 10 minutes to $6.5^{\circ} \mathrm{C}$ (chest), $7 \cdot 5^{\circ} \mathrm{C}$ (thigh), and $5 \cdot 6^{\circ} \mathrm{C}$ (finger), and by 83 minutes to $5 \cdot 7,7 \cdot 0$, and $5 \cdot 5^{\circ} \mathrm{C}$ respectively. Shivering started after 20 minutes but never caused severe discomfort and the immersion was ended at 83 minutes only because of pain in his feet. Rectal and aural temperatures (see figure) fell by 1.15 and $0.85^{\circ} \mathrm{C}$

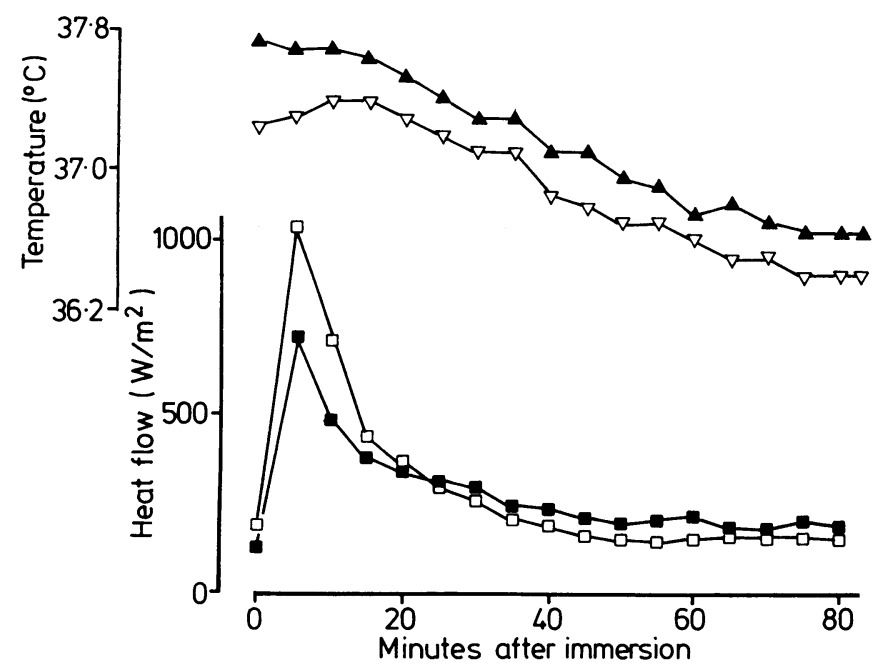

Body core temperatures and surface heat losses in water at $5 \cdot 3-5 \cdot 4^{\circ} \mathrm{C} . \boldsymbol{\Delta}=$ Rectal temperature. $\nabla=$ Zero gradient aural temperature. $\square=$ Heat flow, dorsum of hand. $=$ Heat flow, middle of side of trunk (fluctuations attributable to water flowing under clothing)

respectively but stabilised after 75-83 minutes, with heat flow from the chest stable at about twice resting level. Heat flow from the hand increased after 55 minutes, but only slightly. Metabolic rate, with the subject lying down and relaxed, was $49 \cdot 8 \mathrm{~W} / \mathrm{m}^{2}$. This rose to $199 \cdot 2 \mathrm{~W} / \mathrm{m}^{2} 30-35$ minutes after the start of immersion and to $301 \cdot 1 \mathrm{~W} / \mathrm{m}^{2}$ at $60-65$ minutes. The last value implied whole body insulation of approximately $0 \cdot 102 \mathrm{~W} / \mathrm{m}^{2} /{ }^{\circ} \mathrm{C}$.

\section{Comment}

This subject's account suggests that he had maintained near normal body temperature while swimming for many hours in water at $5-6^{\circ} \mathrm{C}$. In the experimental simulation his temperature stabilised after 75 minutes, with clothing giving only slight thermal protection. His metabolic rate and insulation were then similar to those of fat subjects (mean subcutaneous fat thickness $7-8 \mathrm{~mm}$ ) of earlier experiments exercising in water at $9-12^{\circ} \mathrm{C},{ }^{4}$ but after 30 minutes in water at $5^{\circ} \mathrm{C}$ those subjects, unlike him, showed pronounced increases in peripheral heat loss and progressive body cooling as cold vasodilatation developed. ${ }^{3}$ Absence of this in our subject may have been due in part to his greater fat thickness. Cold vasodilatation is associated with cold paralysis of blood vessels of the extremities, flow then being controlled by more proximal, better insulated arteries. ${ }^{5}$ Thicker subcutaneous fat increases that insulation.

We are greatly indebted to the subject for his cooperation. The study was supported by an MRC grant.

1 Molnar GW. Survival of hypothermia by men immersed in the ocean. $7 A M A$ 1946;131:1046-50. 2 Critchley M. Shipwreck survivors. A medical study. London: J and A Churchill, 1943.

3 Cannon P, Keatinge WR. The metabolic rate and heat loss of fat and thin men in heat balance in cold and warm water. F Physiol 1960;154:329-44.

4 Hayward MG, Keatinge WR. Roles of subcutaneous fat and thermoregulatory reflexes in determining ability to stabilise body temperature in water. $f$ Physiol 1981;320:229-51. 5 Keatinge WR. Survival in cold water. Oxford: Blackwell Scientific, 1969.

(Accepted 17 October 1985)

Department of Physiology, The London Hospital Medical College, London E1 2AD

W R KEATINGE, PHD, MRCP, professor

S R K COLESHAW, PHD, research assistant

CE MILLARD, BSC, research student

Department of Physiology, Medical School, University of Iceland, Iceland J AXELSSON, DPHIL, professor

Correspondence to: Professor Keatinge.

\section{What does "virtually unable to walk" mean?}

Mobility allowance may be awarded to a disabled person aged between 5 and 65 years if he is unable or "virtually" unable to walk. Everyone understands inability to walk but there is no agreement on what constitutes "virtual" inability to walk. It is difficult to quantify gait in a clinically useful way (though it influences decisions in some cases), but I report a study of the other parameters of mobility (distance, time, and speed) mentioned in the mobility allowance regulations.

\section{Patients, methods, and results}

I studied 46 men and 29 women who had been awarded a mobility allowance within the preceding year because they were "virtually unable to walk." Thirty four of the subjects (aged 20-60 years; average 45) were studied in 1977-8 and 41 (20-64 years; average 48) in 1983-4 (the age limit for mobility allowance was increased from 60 to 65 in that time). Thirty six subjects suffered from neurological disorders (stroke in 15, multiple sclerosis in nine), 21 suffered from musculoskeletal conditions (arthritis in 10), seven were lower limb amputees, and five had congenital abnormalities, three cardiac disorders, and three miscellaneous disorders. Their mobility was assessed by asking them to walk at their normal pace on the flat for 12 minutes or until they felt restricted by pain breathlessness, or tiredness. ${ }^{1}$ Distance covered and time taken to first stop or distance covered in 12 minutes were noted and speed to that point calculated.

Three subjects could walk for only one minute, while 28 walked for 12 minutes the average time was 7.7 minutes and the median duration 8.0 minutes. The chart plots the distances and speeds. The average distance walked was $174 \mathrm{~m}$ and the average speed $24 \mathrm{~m} / \mathrm{min}$. Only 27 subjects were below the median values (lines A in the chart) for distance $(120 \mathrm{~m})$ and speed $(20 \mathrm{~m} / \mathrm{min})$. Twenty three subjects were in the middle category between lines $\mathrm{A}$ and $\mathrm{B}$ (the upper quartile values for distance $(240 \mathrm{~m})$ and speed $(34 \mathrm{~m} / \mathrm{min}))$. A further 12 were in the outer category between lines $B$ and $C$, which is the junction of the upper eighth and lower seven eighths for distance $(360 \mathrm{~m})$ and speed $(43 \mathrm{~m} / \mathrm{min})$. There was no difference among major diagnostic groups or between the 1977-8 and 1983-4 samples.

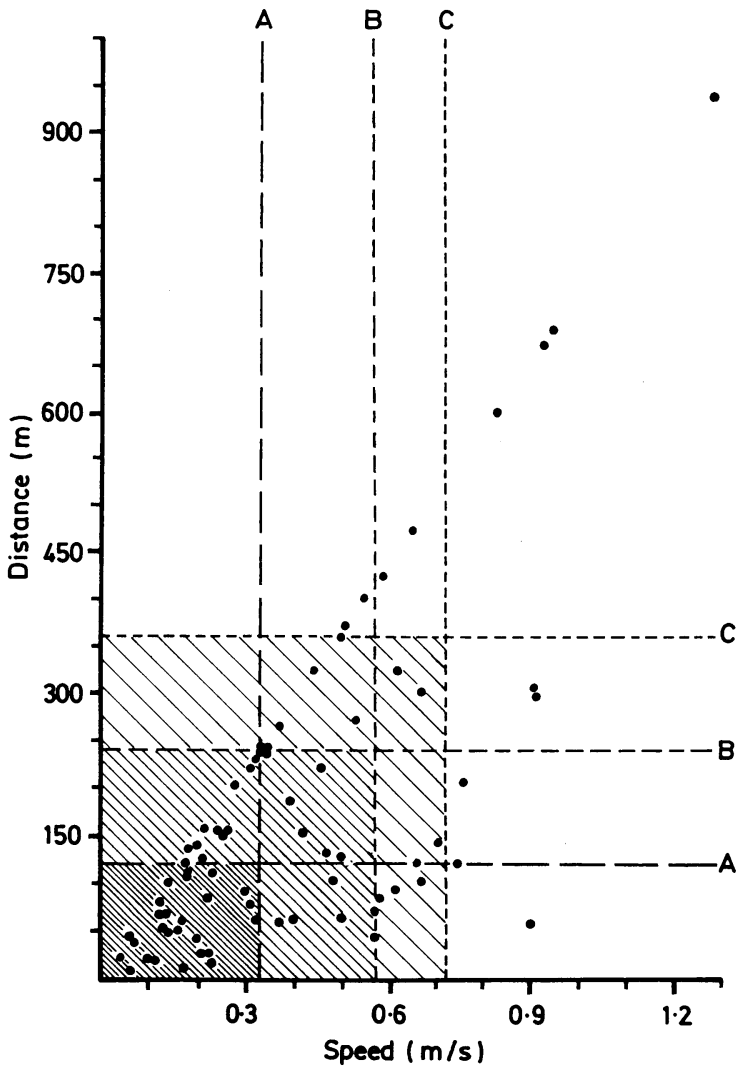

Scattergram of distances walked and speeds of holders of mobility allowances $A=$ Median values. $B=$ Upper quartile values. $C=$ Junction of upper eighth and lower seven eighths of values.

\section{Comment}

"Virtually unable to walk" may be a satisfactory legal term but clinically i is almost meaningless. Guidance notes make it clear that no one factor (such 